\title{
PROTESTO EXTRAJUDICIAL DE CERTIDÃO DE DÍVIDA ATIVA: APERFEIÇOAMENTO DA EXECUÇÃO FISCAL $^{1}$
}

EXTRAJUDICIAL PROTEST FOR ACTIVE DEBT CERTIFICATE: IMPROVING FISCAL

EXECUTION

Gabriel Antonio MONTEIRO²

Silvio Marques GARCIA ${ }^{3}$

ISSUE DOI: $10.21207 / 2675-0104.2018 .774$

\section{RESUMO}

A Dívida Ativa é cobrada segundo as regras previstas na Lei de Execução Fiscal (Lei n. 6.830/1980). No entanto, a dinâmica das relações sociais exige a utilização de meios mais efetivos de cobrança, capazes de garantir a satisfação do crédito tributário de maneira efetiva e célere. Este artigo tem como finalidade expor estudos sobre o protesto extrajudicial de certidão de Dívida Ativa da União como um meio de cobrança do crédito tributário. Tem como objetivo verificar a eficiência do modelo atual de execução fiscal de dívidas ativas da União, bem como analisar a sugestão de desjudicialização da execução fiscal por meio do protesto extrajudicial de certidão de dívida ativa, como um mecanismo de aumento da eficiência do modelo atual.

Palavras-chave: Execução fiscal. Dívida Ativa. Protesto. Crédito Tributário. Cobrança.

\footnotetext{
${ }^{1} \mathrm{O}$ presente artigo sintetiza a monografia de conclusão da pesquisa, realizada para o Programa Interno de Bolsas de Iniciação Científica (PIBIC 2017-2018) da Faculdade de Direito de Franca (FDF), Franca/SP.

${ }^{2}$ Discente da Faculdade de Direito de Franca (FDF), Franca/SP. Bolsista do Programa Interno de Bolsas de Iniciação Cientítica (PIBIC 2017-2018).

${ }^{3}$ Doutorando em Direito (PUC/SP). Mestre em Direito (Unesp). Especialista em Direito Público (Unb/EAGU). Professor da Faculdade de Direito de Franca.
} 


\section{ABSTRACT}

The Active Debt is collected according to the rules provided for in the Tax Enforcement Law (Law n. 6,830/1980). However, the dynamics of social relations require the use of more effective means of collection, capable of guaranteeing the satisfaction of the tax credit in an effective and swift manner. The purpose of this article is to present the studies carried out on the extrajudicial protest of the Federal Active Debt Certificate. Its objective is to verify the efficiency of the current model of fiscal execution of active debts of the Union, as well as to analyze the suggestion of disjudicialization of fiscal execution through out-of-court protest of an active debt certificate, as a mechanism to increase the efficiency of the current model.

Keywords: Fiscal execution. Active debt. Protest. Tax credit. Collection of tax credit.

\section{INTRODUÇÃO}

Os recursos provenientes da tributação são extremamente importantes para a sustentação do Estado, pois é por meio dos tributos arrecadados que o Estado se mantém e desempenha suas funções de garantir à população direitos fundamentais, como saúde, educação, segurança e previdência, proporcionando o desenvolvimento e o bem estar de todos. A execução fiscal é a forma de obter o pagamento da dívida dos contribuintes com o Estado, deflagrada pelo inadimplemento do crédito tributário. A eficiência da recuperação fiscal deve ser a maior possível, a fim de não privar a população dos direitos fundamentais cuja efetivação depende de tais recuros. Não obstante, a duração do processo de execução fiscal costuma ser demasiadamente longa, o que prejudica a a recuperação dos recursos de maneira satisfatória e gera discussão sobre o desempenho do processo de execução fiscal.

Desta forma, o Estado não só fica prejudicado pela ineficiência da recuperação dos créditos, primordiais para a garantia da justiça social, como também sua credibilidade é afetada. Os contribuintes que pagam em dia seus compromissos fiscais deixam de confiar na Administração Tributária, pois notam que seu patrimônio é mal utilizado, havendo pouco ou nenhum retorno em serviços públicos. Isso colabora para a insatisfação dos cidadãos, que se queixam do desperdício de seus preciosos e escassos recursos.

Dentre as sugestões para o aumento de eficiência do processo de execução fiscal, destaca-se a desjudicialização da execução fiscal por meio de alternativas como o protesto extrajudicial da Certidão de Dívida Ativa, ${ }^{4}$ por meio do qual se espera que o Fisco receba seus créditos de

\footnotetext{
${ }^{4}$ Trata-se de artigo que sintetiza a pesquisa realizada junto ao Programa de Iniciação Científica da Faculdade de Direito de Franca.
} 
forma mais ágil e barata em comparação com a via judicial. Por meio da utilização de instrumentos extrajudiciais alternativos mais eficazes, tornase possível aumentar a fluidez destes processos, aperfeiçoando atual sistema de cobrança da dívida ativa, regido pela Lei n. 6.830/1980.

Haja vista o momento econômico e social em que o Brasil está, o Estado e a população brasileira sofrem com as consequências da falta de celeridade e eficiência do modelo atual de execução fiscal, caracterizado pela burocracia do Poder Judiciário, pelo excesso de judicialização e pela pouca eficiência do atual modelo de execução fiscal. A utilização do aparato judicial acarreta gastos consideráveis, que consomem recursos que poderiam ser melhor empregados para a satisfação de outras necessidades públicas. A execução fiscal pela via judicial dissemina a falta de credibilidade nas ações do Fisco, bem como a necessidade de suprir a escassez de recursos com o aumento e criação de novos tributos, onerando o contribuinte, já abatido pela carga tributária exageradamente alta. A população sofre com as consequências da má administração dos recursos, num cenário em que o Estado pouco investe nos serviços públicos essenciais, tais como saúde, educação e segurança.

\section{EXECUÇÃO FISCAL}

O Estado possui o poder-dever de tributar para se manter e, principalmente, garantir o bem-estar social de sua população, promovendo a dignidade da pessoa humana. $O$ tributo constitui apropriação, pelo Estado, de parte do patrimônio dos contribuintes. Por isso deve respeitar todos os princípios constitucionais tributários, destacando-se dentre eles o princípio da legalidade. No entanto, as relações entre o Fisco e o contribuinte que dão origem a obrigações tributárias das quais podem surgir conflitos ou questionamentos. Havendo conflito, surgirá consequentemente a necessidade de resolvê-lo segundo a legislação e da forma mais eficiente possível, tendo em vista se tratar de dinheiro público. A respeito do regramento jurídico da relação tributária, ensina Hugo de Brito Machado: ${ }^{5}$

O estabelecimento de normas jurídicas disciplinando as relações entre os homens - no caso do Direito Tributário, entre os que

\footnotetext{
${ }^{5}$ MACHADO SEGUNDO, Hugo de Brito. Processo tributário. 3. ed. São Paulo: Atlas, 2008. p. 217.
} 


\begin{abstract}
corporificam o Estado cobrador de tributos e os que a essa tributação estão submetidos - nem sempre é suficiente para debelar completamente o surgimento de conflitos. Seja por incompreensão do significado das prescrições normativas, seja por incerteza quanto à ocorrência dos fatos sobre os quais tais prescrições incidem, seja ainda por razões outras, tais como o propósito mesmo de exorbitar o poder que se tem (por parte da autoridades fazendárias), ou de se exonerar ilicitamente do ônus tributário (por parte dos contribuintes), o fato é que as normas jurídicas podem ter suas prescrições violadas, fazendo-se necessária a composição do conflito com a restauração do direito malferido.
\end{abstract}

Dentre as diversas formas de conflito que podem ocorrer entre o Fisco e o contribuinte, este estudo tem foco no inadimplemento dos créditos tributários pelo contribuinte. Portanto, o conflito existirá quando o contribuinte, ciente da obrigação tributária, deixa de efetuar o pagamento, gerando prejuízo à arrecadação de receitas públicas que seriam, em tese, destinadas à garantia da função social dos tributos.

Pode-se definir o processo de execução fiscal como "espécie de processo de execução por quantia certa, fundado em título extrajudicial, através do qual se busca a prestação da tutela jurisdicional executiva." 6 $\mathrm{Na}$ execução fiscal, não se busca a certeza a respeito da relação jurídica mas sim a satisfação do crédito não adimplido.

A dívida do contribuinte é documentada na Certidão da Dívida Ativa, que constitui título executivo. A dívida, regularmente inscrita, goza da presunção de liquidez e certeza, dispensando-se a fase de acertamento. Por meio da execução fiscal, o Estado busca o adimplemento do crédito tributário mediante a constrição do patrimônio do executado.

Pois bem, ao analisar-se o panorama da execução fiscal na Justiça Federal, no relatório Justiça em Números, realizado pelo CNJ (2010), verifica-se que $34,6 \%$ da carga processual do Judiciário corresponde a executivos fiscais. ${ }^{7}$ Trata-se de quantidade espantosa de processos, mesmo se for considerada a potencialidade infinita de conflitos nas relações humanas.

Boaventura de Sousa Santos alerta que a "pressão quantitativa que recai sobre os tribunais e sobre os juízes contribuiu para degradar as

\footnotetext{
${ }^{6}$ MACHAdO SEGUNDO, Hugo de Brito. Processo tributário. 3. ed. São Paulo: Atlas, 2008. p. 234.

${ }^{7}$ CUNHA, Alexandre dos S.; KLIN, Isabela do Valle; PESSOA, Olivia A. G. Custo e tempo do processo de execução fiscal promovido pela Procuradoria-Geral da Fazenda Nacional. Brasília: IPEA, 2011.
} 
condições de funcionamento da administração da Justiça, a maioria das vezes em detrimento da qualidade necessária à função jurisdicional." 8

A elevada carga de processos, combinada com fatores como a falta de servidores e a urgência em satisfazer o crédito público são as características de um sistema processual tributário caótico.

$\mathrm{O}$ processo de execução fiscal possui etapas que influenciam tanto no valor médio da ação, como no tempo de tramitação. Destaca-se inicialmente a citação, seguida de localização de bens, penhora, embargos e leilão. Todavia, é preciso ter em mente que tais etapas, em geral, ou se mostram infrutíferas ou acarretam mais ônus que bônus, de modo que a satisfação integral dos créditos do credor tende a ser irrisória. ${ }^{9}$

No âmbito da Justiça Federal, foram observadas, ao todo, quinze etapas, com as quais calcularam-se as frequências médias prováveis de cada uma delas, de acordo com a amostra e, estabelecida essa frequência, houve o estudo dos tempos necessários ao cumprimento de cada uma dessas etapas, o que resultou em um tempo médio total de tramitação do processo de 2.989 dias ou oito anos, dois meses e nove dias. $^{10}$

A partir desses dados, foi possível determinar o custo médio do processo de execução fiscal, na Justiça Federal, no valor de R $\$ 4.684,39$ (quatro mil, seiscentos e oitenta e quatro reais e trinta e nove centavos). ${ }^{11}$

É possível também concluir que a execução fiscal, enquanto modelo processual para a recuperação de créditos da Fazenda Pública, não possui a eficácia necessária e não atende à relação custo/benefício, podendo-se apontar a necessidade de desjudicialização da cobrança da Dívida Ativa.

Tais informações comprovam a crise da execução fiscal brasileira, que constitui, na prática, um processo em que dificilmente o Fisco recebe seu crédito, cabendo ressaltar ainda que não é de se admitir um procedimento tão moroso e burocrático, tratando-se de dinheiro público.

\footnotetext{
${ }^{8}$ SANTOS, Boaventura de Sousa. Os actos e os tempos dos juízes: contributos para a construção de indicadores da distribuição processual nos juízos cíveis. Coimbra: Observatório Permanente da Justiça Portuguesa, 2005. p. 23.

${ }^{9}$ CUNHA, Alexandre dos S.; KLIN, Isabela do Valle; PESSOA, Olivia A. G. Custo e tempo do processo de execução fiscal promovido pela Procuradoria-Geral da Fazenda Nacional. Brasília: IPEA, 2011. p. 18-19.

${ }^{10}$ Ibidem. p. 21-22.

${ }^{11}$ Ibidem. p. 25.
} 


\section{CONSEQUÊNCIAS}

Conforme anteriormente apontado, as intercorrências e dificuldades inerentes à execução fiscal acaretam não só consequências inter partes, mas se estendem erga omnes.

$\mathrm{O}$ custo unitário do processo $(\mathrm{R} \$ 5.606,67)$, a duração média ( 8 anos, 2 meses e 9 dias), o baixo índice de recuperação, a falta de critérios rigorosos em programas de parcelamento, como o REFIS, entre outros fatores, geram a ineficácia dos meios usuais de cobrança, que não têm funcionado de forma eficiente, acarretando não só prejuízo ao patrimônio público, mas principalmente a premiação do mau pagador.

A grande quantidade de ações fiscais aumenta a morosidade da Justiça como um todo, já considerada lenta. Ao premiar o mau pagador, promove a injustiça fiscal e de priva a população de direitos básicos por falta de recursos, além de sobrecarregar os juízes, alongando o tempo necessário para a entrega da prestação jurisdicional em outras espécies de conflitos, até mesmo nas relações privadas.

Segundo Jules Michelet Pereira Queiroz e Silva, ${ }^{12}$

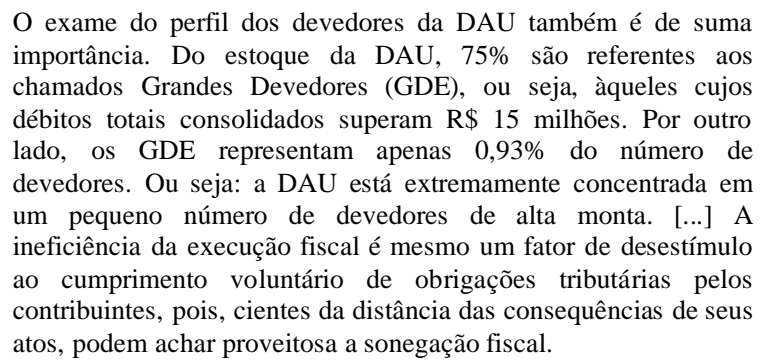

Tal situação constitui afronta ao princípio da livre concorrência, garantido na CF, em seu artigo 170, inciso IV. Não bastasse a alta carga tributária, o pequeno empreendedor ainda tem de disputar o mercado com quem tem mais condições financeiras e pode protelar ou mesmo deixar de pagar tributos, ocultando o patrimônio ou usando dos mais diversos meios para subtrair-se à execução forçada do crédito. A conta não fecha só nos cofres públicos, pois o desestímulo do pequeno e médio empreendedor gera estagnação da economia. A população é quem paga o

\footnotetext{
${ }^{12}$ SILVA, Jules Michelet Pereira Queiroz e. Execução fiscal: eficiência e experiência comparada. Brasília: Câmara dos Deputados, 2016. p. 6-9.
} 
preço novamente; basta olhar para os números do desemprego ${ }^{13}$ e do fechamento de empresas. ${ }^{14}$

Portanto, o modelo de execução da LEF (Lei n. 6.830/1980), planejado para ser um sistema mais eficiente que o executivo comum previsto no CPC, não atingiu o objetivo para o qual foi planejado, esbarrando em problemas como a burocratização e a alta complexidade dos atos, aos quais se somam o tempo de tramitação do processo, a consequente depreciação dos bens penhorados, o esvaziamento do patrimônio do devedor e, finalmente, a prescrição intercorrente.

Em que pese aos poucos avanços jurisprudenciais, a execução fiscal tomou para si um papel obscuro nos números da Justiça brasileira. É claro que, com base nas consequências apresentadas, o modelo judicial de arrecadação dos créditos públicos precisa ser repensado.

O processo de execução fiscal tornou-se sinônimo de ineficiência, morosidade e inadimplemento, comprovando a lamentável conclusão de que permite a premiação do mau pagador e desestimulando o restante da população ao adimplemento de seus débitos.

As crises econômicas e política que têm afligido o país, somadas à corrupção, criaram o ambiente perfeito para a falta de cidadania fiscal, estimulando o aumento da sonegação e do inadimplemento de tributos e prejudicando a recuperação dos créditos. Dessa forma, urge que novos instrumentos de cobrança e de constrição do patrimônio dos devedores sejam adotados, de modo a promover da forma mais eficiente possível o cumprimento da obrigação tributária, sem, entretanto, desrespeitar a legalidade característica do Estado Democrático de Direito.

\section{PROTESTO EXTRAJUDICIAL DE CERTIDÃO DE DÍVIDA ATIVA}

Um dos meios de assegurar maior eficiência à recuperação os créditos públicos tem sido o protesto extrajudicial de Certidão de Dívida

\footnotetext{
13 Desemprego volta a crescer no primeiro trimestre de 2018. Disponível em: $<$ https://agenciadenoticias.ibge.gov.br/agencia-noticias/2012-agencia-de-noticias/noticias/20995desemprego-volta-a-crescer-no-primeiro-trimestre-de-2018.html>. Acesso em 20 ago. 2018.

${ }^{14}$ Em três anos, 341,6 mil empresas foram fechadas no Brasil, aponta IBGE. Disponível em: $<$ https://g1.globo.com/economia/noticia/em-tres-anos-3416-mil-empresas-foram-fechadas-no-brasilaponta-ibge.ghtml>. Acesso em 20 ago. 2018.
} 
Ativa, com o intuito de dar ao Fisco uma alternativa eficaz para mitigar as perdas do executivo fiscal.

O protesto é definido no artigo $1^{\circ}$ da Lei n. 9.492/1997 (Lei do Protesto) como o "ato formal e solene pelo qual se prova a inadimplência e o descumprimento de obrigação originada em títulos e outros documentos de dívida."

Trata-se de instrumento jurídico tradicionalmente utilizado no âmbito do direito privado. No entanto, passou a ser também utilizado pelo Direito Público como meio alternativo à Execução Fiscal para obter o adimplemento da Dívida Ativa tributária e não tributária.

A possibilidade do protesto de CDA surgiu legalmente com a Lei n. 12.767/2012, que inseriu o parágrafo único no artigo $1^{\circ}$ da Lei $n$. 9.492/1997, incluindo de modo expresso as Certidões de Dívida Ativa CDA no rol dos títulos sujeitos a protesto.

Uma das características do protesto extrajudicial é sua natureza bifronte, que corresponde à ideia de que "o protesto, além de representar instrumento para constituir em mora elou comprovar a inadimplência do devedor, é meio alternativo para o cumprimento da obrigação". ${ }^{15} \mathrm{Tal}$ conceito foi explorado pelo Ministro Herman Benjamin, relator do Recurso Especial n. 1.126.515-PR, em que foi superada a jurisprudência então sedimentada no próprio Superior Tribunal de Justiça, que não admitia o protesto de Certidão de Dívida Ativa.

Cumpre ressaltar que a utilização do protesto não era pacífica no Direito brasileiro, até que, em 09.11.2016 o Supremo Tribunal Federal, por maioria, julgou improedente a Ação Direta de Inconstitucionalidade n. 5.135-DF, por meio da qual se pretendia a declaração de inconstitucionalidade do parágrafo único no artigo $1^{\circ}$ da Lei n. 9.492/1997, inserido pela Lei n. 12.767/2012. Na ocasião, foi fixada a seguinte tese: "O protesto das Certidões de Dívida Ativa constitui mecanismo constitucional e legítimo, por não restringir de forma desproporcional quaisquer direitos fundamentais garantidos aos contribuintes e, assim, não constituir sanção política."16

\footnotetext{
${ }^{15}$ BRASIL. Superior Tribunal de Justiça. Recurso Especial n. 1.126.515-PR (2009/0042064-8). Recorrente: Município de Londrina. Recorrido: Protenge Engenharia de Projetos e Obras Ltda. Relator: Ministro Herman Benjamin, SEGUNDA Turma, julgado em 3/12/2013, publicado em $16 / 12 / 2013$. Disponível em: https://ww2.stj.jus.br/processo/pesquisa/?src=1.1.3\&aplicacao=processos.ea\&tipoPesquisa=tipoPesq uisaGenerica\&num_registro=200900420648>. Acesso em 20 ago. 2018.

${ }^{16}$ BRASIL. Supremo Tribunal Federal. Ação Direta de Inconstitucionalidade n. 5.135-DF, Relator: Ministro Roberto Barroso, julgado em 9/11/2016, publicado em 11/11/2016. Disponível em: <
} 
A ADI havia sido manejada pela Confederação Nacional da Indústria, impugnando o protesto de CDA, por entender que tal meanisto constitui sanção política, pois o Fisco estaria coagindo o devedor a pagar o tributo, e que tal prática violaria direitos fundamentais dos contribuintes, como o princípio do devido processo legal e o princípio da proporcionalidade. Porém, o protesto de CDA foi considerado constitucional. A Corte Máxima entendeu que o protesto não configura sanção política nem viola direitos fundamentais dos contribuintes, os quais deram ensejo à cobrança tributária.

Tal julgado constitui um marco para a Execução Fiscal e demonstra que os tribunais pátrios já reconhecem os prejuízos sociais acarretados pela Execução Fiscal na via judicial. Assim, o protesto de CDA se apresenta como mecanismo apto a desafogar grande parte dos entraves burocráticos da execução e assegurar que o crédito ingresse nos cofres públicos e possa ser distribuído para a realização das políticas públicas e garantia a função social do tributo.

\section{EFICIÊNCIA DO PROTESTO EXTRAJUDICIAL DE CDA NA RECUPERAÇÃO DE CRÉDITOS PÚBLICOS}

A fim de comprovar a eficácia do protesto extrajudicial como instrumento de aperfeiçoamento da execução fiscal, foram utilizados dados da Procuradoria-Geral da Fazenda Nacional, publicados em levantamentos realizados desde 2013 até o primeiro trimestre de 2018. O registro da atuação dos procuradores e servidores administrativos da PGFN, conhecido como PGFN em Números, ${ }^{17}$ permite conhecer os valores correspondentes à recuperação dos créditos da Fazenda Federal. Por meio de tal análise, foi possível observar a crescente recuperação de créditos públicos, ou seja, o aumento da arrecadação, por meio da utilização de tal instrumento.

Em março de 2013, quando foi iniciado o projeto do Protesto Extrajudicial de Certidões de Dívida Ativa da União pela Procuradoria

\footnotetext{
http://redir.stf.jus.br/estfvisualizadorpub/jsp/consultarprocessoeletronico/ConsultarProcessoEletronic o.jsf?seqobjetoincidente $=4588636>$. Acesso em 12 ago. 2018 .

17 Disponível em: <http://www.pgfn.fazenda.gov.br/acesso-a-informacao/institucional/pgfn-emnumeros-2014>. Acesso em 15 ago. 2018.
} 
Geral da Fazenda Nacional, até outubro de 2015, foram recuperados R\$ 728.260.828,54. ${ }^{18}$

Em 2016, o total arrecadado, por meio do protesto extrajudicial, correspondeu ao valor de $\mathrm{R} \$ 712.010 .612,63^{19}$. Note-se que só o arrecadado em 2016 ficou muito próximo ao arrecadado em aproximadamente um ano e sete meses (março/2013 a outubro/2015). Já em 2017, o valor total arrecadado por protesto foi de $\mathrm{R} \$$ 867.778.564,3020.

O primeiro trimestre de 2018 foi responsável pelo recorde de recuperação, mais de $\mathrm{R} \$ 7,12$ bilhões, representando um crescimento de $73,2 \%$ em relação ao mesmo período de 2017 , que atingiu o valor de $\mathrm{R} \$$ 3,999 bilhões. Deste montante, o recuperado com o protesto aumentou $21,8 \%$, também com relação ao mesmo período, passando de $\mathrm{R} \$ 210,3$ milhões para R\$256,2 milhões ${ }^{21}$.

A evolução da recuperação do crédito fazendário federal demonstra a eficiência da adoção de instrumentos alternativos à Execução Fiscal para a cobrança de créditos públicos. Assim, qualquer meio legal, proporcional e eficiente deve ser considerado um instrumento viável à Administração Pública com a finalidade de recuperar seus créditos, pois é "a partir da conscientização de que a tributação existe como uma forma de realização da justiça social, a fim de que se alcance o propósito estabelecido no Texto Constitucional de uma vida digna para todos." 22

Portanto, pode-se afirmar que o protesto de CDA é um meio de desjudicialização da execução físcal que traz resultados consistentes e promissores para reduzir o inadimplemento fiscal. Sua forma simplificada aliada ao seu trâmite ágil garante ao Fisco uma ferramenta importante para a recuperação do dinheiro público, que poderá ser utilizado de forma mais ágil e eficipente para a garantia da dignidade humana da população brasileira.

18 Disponível em: < https://www.ibet.com.br/protesto-de-cdas-possui-taxa-de-recuperacao-de-19>. Acesso em 15 ago. 2018.

${ }^{19}$ BRASIL. Procuradoria-Geral da Fazenda Nacional. PGFN em Números 2017. Brasília: PGFN, 2017. Disponível em: <http://www.pgfn.fazenda.gov.br/acesso-a-informacao/institucional/pgfn-emnumeros-2014/PGFN\%20em\%20Numeros\%202017.pdf/view>. Acesso em 15 ago. 2018.

${ }^{20}$ BRASIL. Procuradoria-Geral da Fazenda Nacional. PGFN em Números 2018. Disponível em: <http://www.pgfn.fazenda.gov.br/acesso-a-informacao/institucional/pgfn-em-numeros-

2014/pgfn_em_numeros_final_2_web.pdf/view>. Acesso em 15 ago. 2018.

21 Disponível em: <http://www.pgfn.fazenda.gov.br/noticias/2018/pgfn-divulga-levantamento-darecuperacao-no-1o-trimestre-de-2018>. Acesso em 15 ago. 2018.

${ }^{22}$ GRUPENMACHER, Betina Treiger. Tributação e direitos fundamentais. In: FISCHER, Octavio Campos (Coord.). Tributos e direitos fundamentais. São Paulo: Dialética, 2004. p. 9. 


\section{CONSIDERAÇÕES FINAIS}

O principal objetivo deste trabalho foi avaliar a viabilidade do protesto de Certidão de Dívida Ativa, em função da ineficiência do sistema trazido pela Lei de Execução Fiscal. De acordo com os dados apresentados, a utilização do meio judicial para recuperar os créditos públicos não tem apresentado os resultados esperados para enfrentar a crise fiscal e possibilitar a arrecadação dos valores necessários para o cumprimento das necessidades públicas.

Dentre as consequências da ineficiência da cobrança judicial, podem ser citados a esccassez de recursos para a realização de políticas públicas, a necessidade de manutenção da carga tributária elevada (em função da evasão fiscal e do inadimplemento do crédito tributário), o expressivo número de créditos alcançados pela prescrição, $\mathrm{o}$ alto custo do serviço judiciário necessário para a movimentação da execução fiscal, a desvalorização dos bens penhorados (em razão da morosidade processual), a utilização, pelos devedores, de expedientes para a ocultação do patrimônio, a premiação do mau pagador de tributos, a mitigação da cidadania fiscal e a injustiça fiscal.

Assim, o processo de execução fiscal não recupera de forma satisfatória os créditos públicos, acarretando a necessidade de aplicar métodos menos burocráticos e mais eficientes na cobrança da Dívida Ativa. Dentre as formas possíveis, tem se destacado o protesto extrajudicial da certidão de dívida ativa, legalmente admitido em 2012.

Dados apresentados pela Procuradoria-Geral da Fazenda Nacional demonstram que o protesto de CDA surpreendeu a todos desde seus primeiros resultados, mostrando-se rápido, eficiente e barato, características que não estão presentes no processo de execução fiscal.

Conclui-se, a partir da análise apresentada, que o protesto de Certidão de Dívida Ativa é um meio legal e ágil para reorganizar o sistema de cobrança fiscal, a fim de se buscar a modernidade. A utilização de meios alternativos de cobrança tem aumentado continuamente a arrecadação, mostrando-se importantes instrumentos para a recuperação do dinheiro público, que poderá ser utilizado de forma mais ágil e eficiente para a garantia da dignidade humana da população brasileira. 


\section{REFERÊNCIAS}

BRASIL. Procuradoria-Geral da Fazenda Nacional. PGFN em Números 2017. Brasília: PGFN, 2017. Disponível em: <http://www.pgfn.fazenda.gov.br/acesso-a-informacao/institucional/pgfn-emnumeros-2014/PGFN\%20em\%20Numeros\%202017.pdf/view>. Acesso em 15 ago. 2018.

PGFN em Números 2018. Disponível em: <http://www.pgfn.fazenda.gov.br/acesso-ainformacao/institucional/pgfn-em-numeros-2014/pgfn_em_numeros_final_2_web.pdf/view $>$. Acesso em 15 ago. 2018.

Superior Tribunal de Justiça. Recurso Especial n. 1.126.515-PR (2009/0042064-8). Recorrente: Município de Londrina. Recorrido: Protenge Engenharia de Projetos e Obras Ltda. Relator: Ministro Herman Benjamin, SEGUNDA Turma, julgado em 3/12/2013, publicado em 16/12/2013. Disponível em: <

https://ww2.stj.jus.br/processo/pesquisa/?src=1.1.3\&aplicacao=processos.ea\&tipoPesquisa=tipoPesq uisaGenerica\&num_registro=200900420648>. Acesso em 20 ago. 2018.

Supremo Tribunal Federal. Ação Direta de Inconstitucionalidade n. 5.135-DF, Relator: Ministro Roberto Barroso, julgado em 9/11/2016, publicado em 11/11/2016. Disponível em: < http://redir.stf.jus.br/estfvisualizadorpub/jsp/consultarprocessoeletronico/ConsultarProcessoEletronic o.jsf?seqobjetoincidente $=4588636>$. Acesso em 12 ago. 2018.

CUNHA, Alexandre dos S.; KLIN, Isabela do Valle; PESSOA, Olivia A. G. Custo e tempo do processo de execução fiscal promovido pela Procuradoria-Geral da Fazenda Nacional. Brasília: IPEA, 2011.

GRUPENMACHER, Betina Treiger. Tributação e Direitos Fundamentais. In: FISCHER, Octavio Campos (Coord.). Tributos e Direitos Fundamentais. São Paulo: Dialética, 2004. p. 9-17.

MACHADO, Hugo de Brito. Curso de direito tributário. 20. ed. São Paulo: Malheiros, 2002.

MACHADO SEGUNDO, Hugo de Brito. Processo Tributário. 3. ed. São Paulo: Atlas, 2008.

SANTOS, Boaventura de Sousa. Os actos e os tempos dos juízes: contributos para a construção de indicadores da distribuição processual nos juízos cíveis. Coimbra: Observatório Permanente da Justiça Portuguesa, 2005.

SILVA, Jules Michelet Pereira Queiroz e. Execução Fiscal: eficiência e experiência comparada. Brasília: Câmara dos Deputados, 2016Este artigo é uma produção vinculada ao Programa de Iniciação Científica - Do Curso de Direito da Faculdade de Direito de Franca. 